\title{
Ergonomic risk factors and musculoskeletal disorders in bank staff: an interventional follow-up study in Iran
}

\author{
Majid Motamedzadeh ${ }^{1}$ (D) Mahdi Jalali ${ }^{2,3}$ (D), Rostam Golmohammadi ${ }^{4}$, Javad Faradmal ${ }^{5}$ (D), \\ Hamid Reza Zakeri ${ }^{6}$ and Iman Nasiri ${ }^{7 *}$
}

\begin{abstract}
Background: Long-term use of computer in a static mode may cause musculoskeletal disorders (MSDs) in bank staff. Considering the high number of bank employees in different countries, such as Iran, the risk factors of these disorders should be investigated in order to implement interventions required to reduce the risk factors. This study aimed to examine the risk factors of MSDs using the Rapid Office Strain Assessment (ROSA) method and to perform an ergonomic intervention program with banking staff in Iran.
\end{abstract}

Methods: This interventional study was conducted on 277 bank employees in Iran. Subjects were randomly divided into three groups, including a control group (without any intervention), an educational intervention (EI) group, and a group receiving both educational and physical intervention (EPI). Before and after the intervention, the ROSA method and Nordic questionnaire were used to assess the risk factors of MSDs in office jobs and to investigate the prevalence of MSDs. Data were collected 2 weeks before and 9 months following the intervention.

Results: Before the intervention, the mean score of ROSA at workstations of all groups was above five with high risk. Nine months after the start of the intervention, there was a significant decrease in the mean ROSA score and its components in the two groups that received the intervention, which was statistically significant $(P<0.001)$. The results of the study of the prevalence of MSDs in the employees-before the intervention-indicate that the highest prevalence of MSDs in the control group was in areas of the neck (67.1\%), back (64.4\%), and lower back (63\%). In the El group, the highest prevalence of MSDs was in the neck (65.2\%), lower back (61.6\%), and back (60.7\%) areas. In the EPI group, the discomfort areas were the neck (68.5\%), shoulders (66.3\%), and lower back (60.9\%). Nine months after the intervention, there was a significant decrease in the prevalence of MSDs in the neck, shoulders, and lumbar regions of staff who received the intervention $(P<0.05)$.

Conclusion: Nine months after performing the interventions, there was a relative improvement in workstations and prevalence of MSDs in various areas within the bodies of the bank staff. This study showed that using the ROSA method is appropriate for assessing the risk factors of office work and that it can identify deficiencies in workstations. These defects can be addressed by designing and implementing an El program together with physical interventions according to the components of the ROSA method.

Keywords: Bank staff, Educational intervention, Physical intervention, Musculoskeletal disorders, Rapid Office Strain Assessment (ROSA)

\footnotetext{
* Correspondence: $m$ _jalali63_hse@yahoo.com

${ }^{7}$ Department of Ergonomics, Health Sciences Research Center, School of Health, Hamadan University of Medical Sciences, P.O. Box 65175-4171,

Hamadan, Iran

Full list of author information is available at the end of the article
}

\section{Springer Open}

(c) The Author(s). 2021 Open Access This article is licensed under a Creative Commons Attribution 4.0 International License, which permits use, sharing, adaptation, distribution and reproduction in any medium or format, as long as you give appropriate credit to the original author(s) and the source, provide a link to the Creative Commons licence, and indicate if changes were made. The images or other third party material in this article are included in the article's Creative Commons licence, unless indicated otherwise in a credit line to the material. If material is not included in the article's Creative Commons licence and your intended use is not permitted by statutory regulation or exceeds the permitted use, you will need to obtain permission directly from the copyright holder. To view a copy of this licence, visit http://creativecommons.org/licenses/by/4.0/. 


\section{Introduction}

People in their workplace routinely deal with a range of harmful occupational factors including chemicals (dust, gases, and vapors), physical hazards (noise, ionizing radiation, and inappropriate weather conditions), and psychologic and ergonomic factors (improper posture, stress, and high mental workload) [1-4]. Exposure to these factors can cause a variety of occupational complications and diseases such as respiratory diseases, musculoskeletal disorders (MSDs), physiological disorders, and cancer $[1,5,6]$.

MSDs are among the most important causes of occupational injury and disability in many industries in both developed and developing countries. This results in high economic costs for these industries [7]. Currently, controlling and reducing MSDs in the workforce is one of the most important global concerns for experts in ergonomics. The importance of controlling and reducing these disorders is so high that many countries consider the prevention of work-related MSDs among the workforce as one of the national priorities [8-10]. According to surveys by the $\mathrm{WHO}$, as well as the documentations provided by this organization in 2013, work-related MSDs are at second place of occupational diseases following occupational respiratory diseases [11].

The most common equipment used in most workplaces, especially banks, is the computer. This has increased exponentially over the last 20 years [12-14]. According to a report by the National Bureau of Statistics of China, in 2007, $60 \%$ of workers in the workplace use computers. This increases to $88 \%$ in business and economic services [15]. More than half of employees in European Union member countries use computers during their workday [16]. Numerous studies have shown that computer use is associated with an increase in the prevalence of MSDs. The results of longitudinal followup studies of 3 months to 5 years indicate an increased risk of pain in the neck and shoulders among computer users [17, 18]. Giahi et al. (2014) -in a study on bank users in Iran-showed that $70.2 \%$ of subjects had discomfort in at least one area of the body. The duration of working with a computer and inadequate resting time were the most important factors contributing to discomfort [19].

The most important physical risk factors that cause MSDs in many occupations include repetitive activity, excessive force, improper posture, contact pressures, vibration, and physical fatigue [20]. Additionally, factors such as age, sex, obesity, physical activity, and smoking (as individual factors); factors associated with workstation design such as duration of computer use, frequency of rest, keyboard usage, status of the computer monitor, and the type and use of computer-connected devices; and psychosocial factors have also been implicated in the development of MSDs [13].

Although there is growing interest among employers to improve office workplaces, few studies have examined the effects of ergonomic interventions on employees' health. However, recent evidence suggests that ergonomic training and ergonomic design of workstations and office buildings can be useful in preventing and reducing MSDs and their associated symptoms in office settings [21]. There are various ways to reduce or eliminate the risk factors of MSDs in the office environment. The ergonomic design of the office workstations is the most effective intervention method to completely eliminate the risk factors of the office environment. However, this method is costly and time consuming. Therefore, the most sensible approach is to provide training to employees and the correct context for their own workplace settings [13]. However, there may be reasons for the inability of staff to adjust their workspaces, such as using the unadjusted equipment, workspace constraints, lack of ergonomic equipment, and a lack of ergonomic information provided to the office workers. Consequently, using the educational intervention (EI) along with physical intervention (PI) can be considered the most effective measure in improving the ergonomic conditions of office workstations. This can aid the elimination reduction of the ergonomic risk factors among office workers [22]. The present study aims to (1) assess the ergonomic risk factors of office workstations using the ROSA tool, (2) determine the effect of office ergonomics training on the improvement of workstations by staff, and (3) perform PIs to improve risk factors.

\section{Methods}

\subsection{Study design, population, and sample}

This interventional study was conducted on 277 office workers at a large bank in Iran. The participants were divided into three groups including the control group, EI group, and educational and physical intervention (EPI) group. The criteria for selecting the subjects included staff with office jobs who work with computers for at least $3 \mathrm{~h}$ or more per day with work experience of at least 1 year. Exclusion criteria also included refusing of participants during the study and non-occupational MSDs (due to an accident) during the study. Consequently, at the beginning of the study, of 1050 bank staff, 110 participants were selected for each group (330 people in total) using a systematic random sampling method. This study was approved by the Ethics Committee of the Hamadan University of Medical Sciences, Hamadan, Iran. All of the participants completed the informed consent and signed it. 


\subsection{Data collection}

After specifying the samples, the study was conducted in two phases as follows.

\subsubsection{Phase l: assessment of the work environment}

2.2.1.1 Collection of demographic and occupational data For this purpose, a demographic characteristic questionnaire that was designed including the variables of age, sex, height, weight, and work experience was used.

2.2.1.2 Assessing the prevalence of MSDs The Nordic musculoskeletal questionnaire was used to determine the prevalence of MSDs before and after interventions [23]. The questionnaire consists of two general and specific sections, of which only the general section was considered based on the purpose of the study. The questionnaire was completed through direct interviews with the subjects, and the prevalence of MSDs over the year was recorded. Figure 1 presents this questionnaire.

A total of 330 questionnaires were distributed to all subjects 2 weeks before the intervention, as follows:

A total of 110 questionnaires were distributed among the 110 employees selected in the control group. Following the preintervention phase, 90 questionnaires were completed (81.8\% response rate). After 9 months of intervention, the questionnaires were redistributed. This time, only 73 members of the control group completed the questionnaire (81.1\% response rate). Consequently, in this group, 37 cases were excluded-compared with the beginning of the study-and 73 cases were evaluated as the final number of the control group.

A total of 120 questionnaires were distributed among 120 employees present in the EI group. At the conclusion of the preintervention phase, 112 questionnaires were completed (93.3\% response rate). After 9 months of intervention, the questionnaires were redistributed, and all of 112 participants completed the questionnaire (100\% response rate). Consequently, eight staff were excluded from the studycompared with the beginning of the study-and 112 staff were studied as the final number of the EI group.

A total of 110 questionnaires were distributed among 110 employees in the EPI group. At the end of the preintervention phase, 100 questionnaires were completed (90.1\% response rate). After 9 months of intervention, the questionnaires were redistributed, and only 92 individuals completed the questionnaire (92\% response rate). Consequently, 18 participants were excluded from the study-compared with the beginning of the study-and 92 staff were evaluated as the final number of the EPI group. Figure 2 presents the study flow diagram.

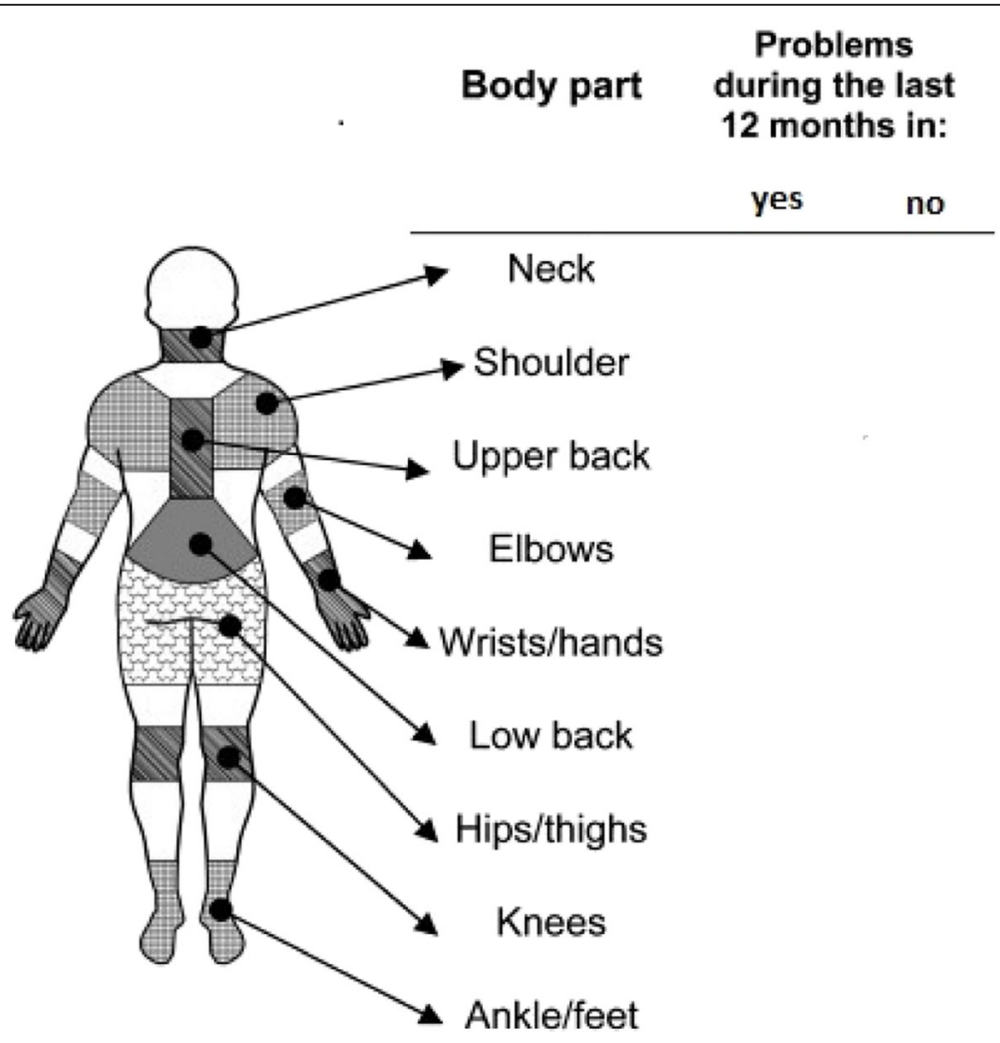

Fig. 1 NORDIC questionnaire 


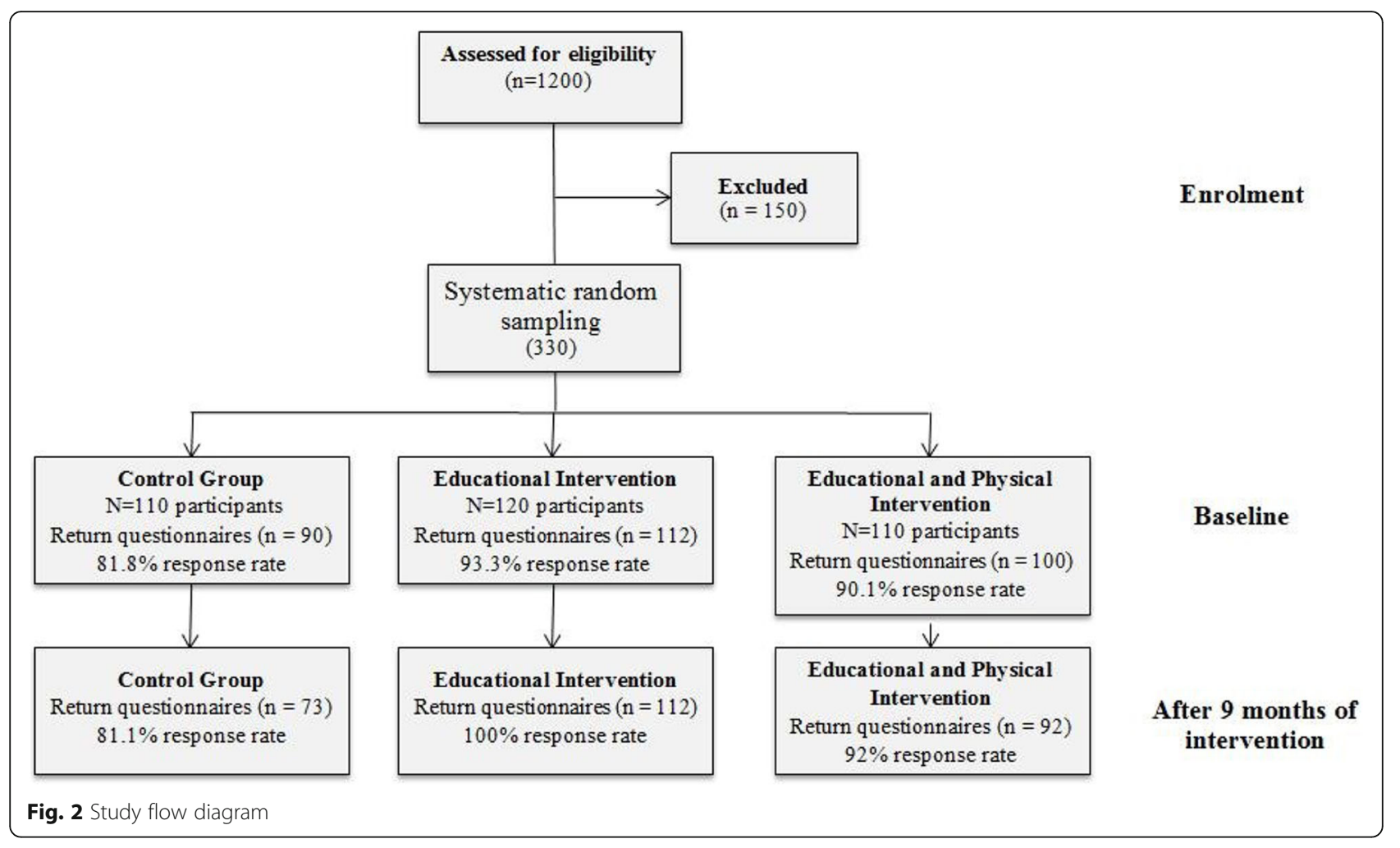

2.2.1.3 Workstation ergonomic risk analysis and determination of risk levels The Rapid Office Strain Assessment (ROSA) method was used to identify the risk factors for office work and prioritize the optimal fit between staff and workstation equipment (24). This method was developed by Sonne et al. in 2011. ROSA is a pen-and-paper approach based on Canada's CSA-Z412 standard, which divides the workstation into several segments, including chair components, monitor, telephone, mouse, and keyboard, and determines the risk level of each section. A ROSA score above five indicates that the risk level of work is high and immediate correction is required (24).

\subsubsection{Phase II: intervention}

At this stage, workstations were assessed using the ROSA method and risk levels were determined. Subsequently, ergonomic interventions were designed and performed according to the components of the ROSA method for the stations that were diagnosed as requiring intervention.

Interventions that included EPIs were conducted as follows:

2.2.2.1 Educational intervention These interventions consisted of preparing an educational handbook with the topic of office ergonomics distributed among all participants in the EI and EPI groups. The educational content of the handbook was selected on the basis of the design of the workstation by personnel under study-according to the risk factors examined by the ROSA method-and using the office workstation standard provided by the Canadian Standard Association [30]. This handbook included how to set up and place items on the surface of the desk, identifying neutral and inappropriate postures, how to adjust chairs and create appropriate postures while working on chairs, correct posture in the use of the mouse and keyboard, how to place and set up a monitor on the work surface, the proper position of the phone in relation to the position of staff, how to use the phone properly, and the correct place for the holder (sheets holder) on the work surface. After distributing the handbooks to the staff, they were asked to adjust their workstations according to the standards provided, if possible. The researcher transmitted face-to-face training in relation to potential questions for all personnel presentin both interventional groups - to construct a workstation. Another training activity in this phase of the study involved training staff on how to perform soft movements behind their desk. To increase the effectiveness of this approach, ErgoPro software version 2.0-designed for this purpose-was installed on all employees' systems. The software was automatically activated at different times of the day and displayed on the staff computer monitor screen, reminding them of various appropriate training movements practicable behind the desktop. 
2.2.2.2 Physical interventions These interventions included the distribution of spine-fit (ergonomic back support pillow); replacement of ergonomic chairs, keyboards, and mouse pads; adjustment of workstations (such as height and angle of the monitor); positioning of the telephone; ergonomic location of work surface equipment; distribution of ergonomic footstools; distribution of inclined boards to raise the height of the study level; and adjustment of the workstation light to prevent glare. These interventions were performed only in the EPI group that required all or part of these interventions according to the ROSA method and its components. Figure 3 presents a sample of intervention activities.

\subsubsection{Assessing the effectiveness of interventions} Following the intervention, risk factors causing MSDsand their prevalence-were reassessed through the ROSA method and Nordic questionnaire after 9 months of intervention in the study groups. The effectiveness of ergonomic interventions was determined after the interventions, and the data were compared with those before the interventions.

\subsection{Data analysis}

SPSS version 16 was used for data analysis. A one-way ANOVA test was used to compare the mean of quantitative variables such as age, work experience, and body mass index (BMI) between the three groups. The McNemar test was used to compare the ratios in qualitative variables such as MSDs of each organ in each group before and after the intervention. A paired $t$ test was used to compare the mean score of ROSA and each of its components as a quantitative variable before and after the intervention for all three groups. All tests were conducted at a $95 \%$ significance level with $\alpha=5 \%$.

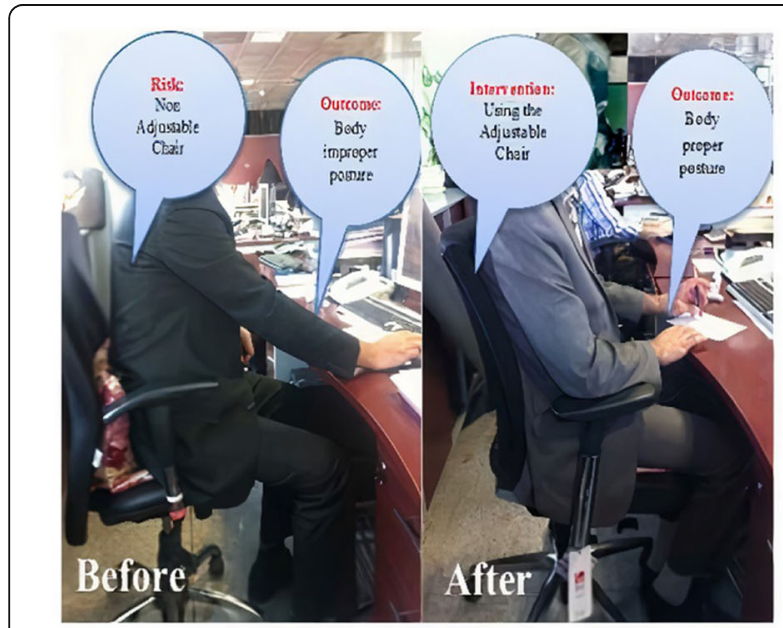

a The effect of char replacement on ROSA nisk score reduction (2-score reduction in chair section)

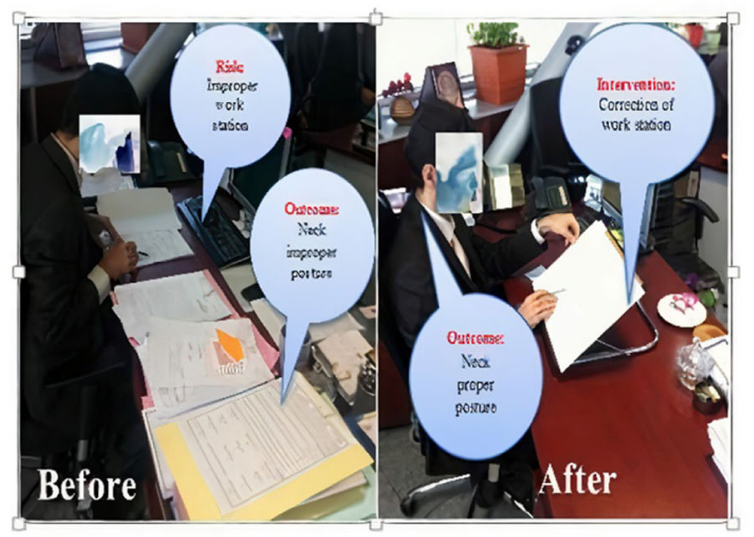

C The effect of uncluned board and proper layout of equpment on desk suface on individual posture

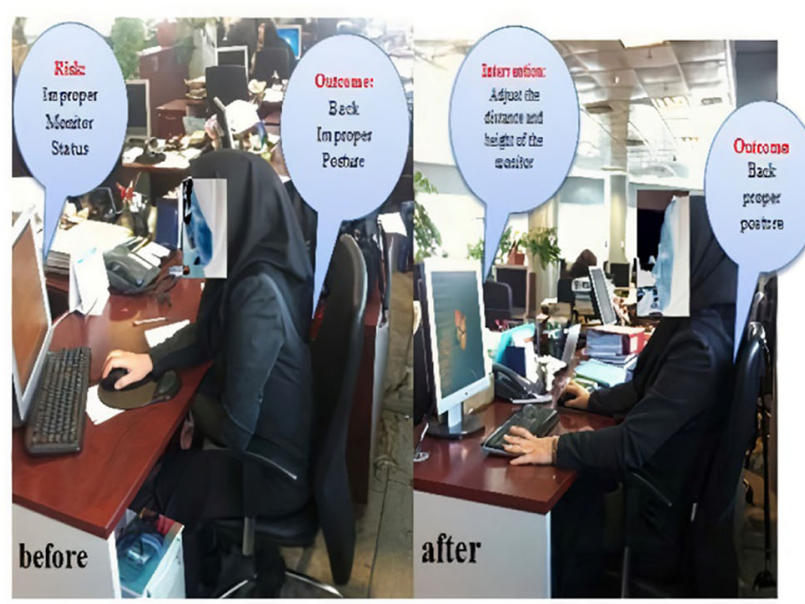

b The effect of monitor adjustment on ROSA risk score reduction (2-score reduction in monitor section)

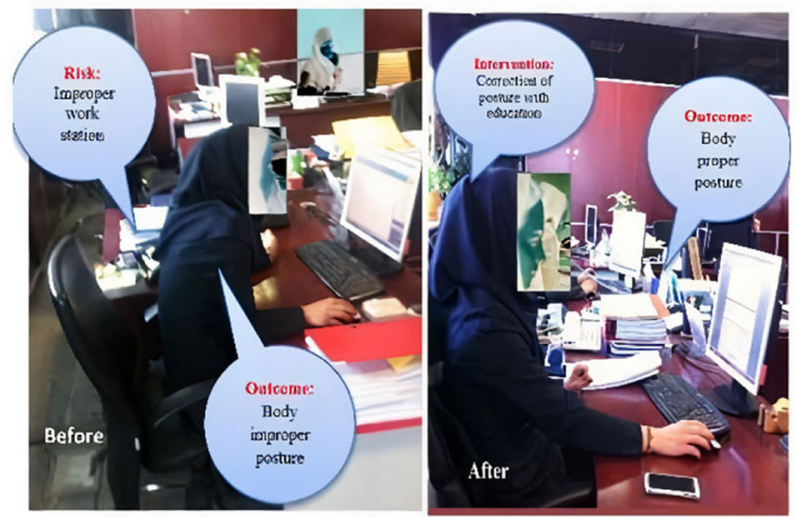

d The effect of channg correctly in decreasing ROSA nsk score (a decrease of 1-score in monitor section and 2-score reduction in chair section)

Fig. 3 The sample of intervention activities (before and after intervention) 


\section{Results}

Table 1 summarizes the demographic characteristics of the bank staff in different groups. The results of the one-way ANOVA indicated that the mean of age, BMI, and work experience were similar between the three groups. There was no significant difference between the three groups $(P>0.05)$.

Table 2 presents the comparative results of the mean ROSA score (and its components in the workstations of staff) of groups before and after the intervention. There was no significant difference between the mean ROSA score and its components in the control group before and after the intervention. The mean score of ROSA and its components in the EI group decreased significantly following the intervention $(P<0.001)$. The mean score of ROSA and its components in the EPI group were remarkably reduced after the intervention that were statistically significant $(P<0.001)$.

Table 3 presents the comparative results of the prevalence of MSDs in the participants, before and after the intervention. The results of the study of the prevalence of MSDs in the employees before the intervention indicated that during the year, the highest prevalence of MSDs in the control group was in the areas of the neck (67.1\%), back (64.4\%), and lower back (63\%). In the EI group, the highest prevalence was in the neck $(65.2 \%)$, lower back (61.6\%), and back (60.7\%) areas. In the EPI group, the discomfort areas were the neck (68.5\%), shoulders (66.3\%), and lower back (60.9\%). The results of the study indicated that (except for the wrist and knee areas) there was a statistically significant difference in the prevalence of MSDs in other areas before and after the intervention in the control group. This difference was due to the increased prevalence of discomfort in these areas $(P<0.05)$. After 9 months of initial evaluation, the incidence of discomfort in all areas of the body, except the wrists and knees, increased in the control group. In the EI group, except for the ankles, the incidence of discomfort was reduced in other areas.
However, this decrease was statistically significant only in the neck, shoulder, and lower back regions $(P<0.05)$. The results of the EPI group suggest that-except for the thighs - the prevalence of discomfort was reduced in the other areas. The decrease was statistically significant in the neck, shoulder, wrist, back, and lower back area $(P<0.05)$.

\section{Discussion}

This study aimed to evaluate the risk factors of MSDs using the ROSA method and the implementation of an ergonomic intervention program in an Iranian bank. The results showed that the mean ROSA score and its components decreased following the intervention in the workstations of the EI group and the EPI group. However, there was no difference in the mean score of ROSA, nor its components in the control group workstations that did not receive any intervention during the study. Furthermore, the prevalence of MSDs in several areas of the body of subjects in the EI group and EPI group decreased significantly after 9 months of intervention. However, some of the MSDs had also increased after 9 months of intervention in the control group.

The results of the study of the prevalence of MSDs in the bank employees before the intervention showed that during the year, the highest prevalence of MSDs-in subjects within the control group-was related to the neck, back, and lower back areas. In the EI group, it was in the neck, lower back, and back regions, and in the EPI group it was in the neck, shoulders, and lower back. This prevalence rate is according to the results of previous studies conducted in this area [24-26]. This may be due to the improper design of workstations for these employees. Office work, because of its occupational nature, often requires a static posture and long durations of sitting on a chair-which has been identified as a major risk factor for neck pain, according to recent studies [27]. Prolonged sitting and inappropriate workstation posture can cause long-term static muscle contraction,

Table 1 Demographic characteristics of employees in a large Iranian Bank by study groups

\begin{tabular}{|c|c|c|c|c|c|c|c|}
\hline Variable & Group & $n$ & Mean & S. deviation & Min & Max & $P$ value ${ }^{*}$ \\
\hline \multirow[t]{3}{*}{ Age (year) } & Control group & 72 & 37.23 & 6.76 & 24 & 61 & 0.068 \\
\hline & El group & 111 & 36.35 & 5.52 & 25 & 50 & \\
\hline & EPI group & 92 & 34.92 & 5.45 & 25 & 65 & \\
\hline \multirow[t]{3}{*}{ BMI } & Control group & 72 & 25.27 & 4.7 & 16.53 & 48.44 & 0.592 \\
\hline & El group & 109 & 25.02 & 3.98 & 18.13 & 36.86 & \\
\hline & EPI group & 88 & 26.52 & 17.55 & 17.63 & 180.56 & \\
\hline \multirow[t]{3}{*}{ Work experience (year) } & Control group & 68 & 12.75 & 5.87 & 3 & 29 & 0.136 \\
\hline & El group & 111 & 12.85 & 6.35 & 1 & 26 & \\
\hline & EPI group & 91 & 11.35 & 4.6 & 1 & 24 & \\
\hline
\end{tabular}


Table 2 Comparative results of mean ROSA score and its components in staff workstations of groups before and after intervention

\begin{tabular}{|c|c|c|c|c|c|c|c|c|c|c|}
\hline \multirow[t]{2}{*}{ Variable } & & \multicolumn{3}{|c|}{ Control group } & \multicolumn{3}{|c|}{ El group } & \multicolumn{3}{|c|}{ EPI group } \\
\hline & & Before & After & $P$ value* & Before & After & $P$ value* & Before & After & $P$ value* \\
\hline \multirow[t]{2}{*}{ Chair } & Mean & 4.41 & 4.6 & 0.12 & 4.63 & 3.82 & $<0.001$ & 4.77 & 3.47 & $<0.001$ \\
\hline & S. deviation & 0.92 & 0.81 & & 0.96 & 0.63 & & 0.87 & 0.63 & \\
\hline \multirow[t]{2}{*}{ Monitor and telephone } & Mean & 4.15 & 4.27 & 0.083 & 3.97 & 1.29 & $<0.001$ & 4.18 & 2.69 & $<0.001$ \\
\hline & S. deviation & 1.32 & 1.27 & & 1.29 & 0.59 & & 1.3 & 0.73 & \\
\hline \multirow[t]{2}{*}{ Mouse and keyboard } & Mean & 3.8 & 3.78 & 0.596 & 3.38 & 2.97 & $<0.001$ & 3.65 & 2.77 & $<0.001$ \\
\hline & S. deviation & 1.3 & 1.22 & & 0.912 & 0.62 & & 1.07 & 0.69 & \\
\hline \multirow[t]{2}{*}{ ROSA score } & Mean & 5.02 & 5.05 & 0.673 & 5.04 & 3.97 & $<0.001$ & 5.3 & 3.57 & $<0.001$ \\
\hline & S. deviation & 1.02 & 1.03 & & 0.99 & 0.59 & & 0.79 & 0.65 & \\
\hline
\end{tabular}

*Paired sample $t$ test

increased pressure on the intervertebral discs, muscle tension on the ligaments and muscles, and reduced flexibility of tissues and can alter the curvature of the spine. These changes can increase the risk of spinal MSDs [28]. In a study conducted by Mohammadipour et al. (2018) of 250 office workers, the prevalence of musculoskeletal discomfort was high in the staff. The prevalence rate was predominately in the lower back and neck [24]. Besharati et al. (2020) similarly highlighted that the prevalence of these disorders among office workers in the neck and shoulder areas was higher than in other areas. This is consistent with the results of the present study [25]. In another study conducted by Giahi et al. (2014), to examine MSDs in computer users of bank office staff, the highest prevalence was reported in the neck, lower back, elbows, and thighs [19].

Studying risk factors causing MSDs preintervention suggested that the mean score of ROSA in workstations of all three groups was above five (high-risk level). However, the mean final score of this method-and its components in the intervention groups-showed a significant decrease following the intervention compared with the time when no intervention was undertaken. However, the mean of this method (and its components) did not change in the control group that did not receive the intervention. These findings indicate the impact of EPIs on reducing ergonomic risk levels in workstations. The lack of employees' awareness of the benefits of ergonomics before doing interventions and the use of nonergonomic equipment-and their insufficient attention to ergonomic issues in the workplace-may be the main reasons for high workstation ergonomic risk score before the intervention. However, increased awareness of employees through education, ergonomic workstation design, physical changes in the workstations and replacement of some non-ergonomic equipment reduced the level of risk to acceptable levels. Poochada et al. (2015) investigated ergonomic risk factors among office workers within telephone centers using the ROSA method. The findings suggested that the majority of people were at a high risk level (above five), and therefore, rapid workstation modification was required [29]. Additionally, the mean ROSA score and its components in the present study are higher than those obtained in

Table 3 Comparative results of prevalence of musculoskeletal disorders in different areas of body in three groups before and after intervention

\begin{tabular}{|c|c|c|c|c|c|c|c|c|c|}
\hline \multirow[t]{2}{*}{ Variable } & \multicolumn{3}{|c|}{ Control group } & \multicolumn{3}{|l|}{ El group } & \multicolumn{3}{|c|}{ EPI group } \\
\hline & Before & After & $P$ value* & Before & After & $P$ value* & Before & After & $P$ value* \\
\hline Neck & $49(67.1)$ & $58(79.5)$ & 0.012 & $73(65.2)$ & $50(44.6)$ & $<0.001$ & $63(68.5)$ & $40(34.4)$ & $<0.001$ \\
\hline Shoulders & $44(60.3)$ & $52(71.2)$ & 0.021 & $67(59.8)$ & $52(46.4)$ & 0.04 & $61(66.3)$ & $42(45.6)$ & $<0.021$ \\
\hline Elbows & $15(20.5)$ & $25(34.2)$ & 0.002 & $21(18.8)$ & $18(16.1)$ & 0.375 & $14(15.2)$ & $11(12)$ & 0.375 \\
\hline Wrist & $38(52.1)$ & $43(58.9)$ & 0.18 & $47(43)$ & $42(37.5)$ & 0.12 & $39(42.4)$ & $22(23.9)$ & $<0.001$ \\
\hline back & $47(64.4)$ & $56(76.7)$ & 0.012 & $68(60.7)$ & $55(49.1)$ & 0.061 & $54(58.7)$ & $44(47.8)$ & 0.038 \\
\hline Lower back & $46(63)$ & $54(74)$ & 0.039 & 69 (61.6) & $52(46.4)$ & 0.042 & $56(60.9)$ & $26(28.2)$ & $<0.001$ \\
\hline thighs & $9(12.3)$ & $19(26)$ & 0.002 & $31(27.7)$ & $20(17.9)$ & 0.054 & 18 (19.6) & $18(19.2)$ & $P>0.05$ \\
\hline Knees & $40(54.8)$ & $37(50.7)$ & 0.549 & $52(46.4)$ & $45(40.1)$ & 0.26 & $47(51.1)$ & $40(43.4)$ & 0.23 \\
\hline Legs and ankles & $16(21.9)$ & $22(30.1)$ & 0.031 & $21(18.8)$ & 22 (19.6) & $P>0.05$ & $23(25)$ & 18 (19.5) & 0.097 \\
\hline
\end{tabular}

*McNemar's test

*Significant values are shown in italics 
the study of Sonne et al. (2012). This indicates a worse condition of workstations in present study compared with Sonne et al. and generally confirms the existence of high risk levels in office settings [30]. Shariat et al. (2018) found that the use of ergonomic modificationalong with the use of stretching exercises-can significantly improve the status of workstations and MSDs prevalence in office workers [31]. The results of similar studies also confirm the positive effect of EPIs on reducing the level of ergonomic risk factors in office work environments. These findings are according to the results of the present study [32].

The results of the present study showed that except for the ankles, the prevalence of disorders in other areas of the body decreased. However, this decrease was statistically significant only in the neck, shoulder, and lower back areas. Ergonomics training is a tool that can be used to increase employee knowledge of how to adjust the layout of work, maintain the most beneficial postures while performing work, correctly use office equipment, and adjust chair and monitor heights. Consequently, the workstation's ergonomic status can be improved by employees [33]. In this study, after enhancing users' knowledge-by distributing training handbooks and helping them adjust workstations by themselves during the study period-there was a significant improvement in working postures, monitor height, telephone usage, and chair adjustment. The decrease in the ROSA score following the intervention also confirms these findings. Consequently, these improved conditions could, after a period of 9 months, cause a significant decrease in the prevalence of MSDs in various areas of the body. These results are according to the results of studies by Robertson et al. (2009), Zeidi et al. (2011), Mahmud et al. (2011), and Motamedzade et al. (2011). These studies all used ergonomics training to improve the ergonomic conditions of workstations and reduce the prevalence of MSDs in computer users and office workers [33-36]. These results are in contrast to a study conducted by Ali Arabian et al. (2013) who did not find EI alone to be a suitable method for reducing MSDs [37].

The results of the study of the prevalence of MSDs in the EPI group-before the intervention and 9 months after the beginning of the intervention-showed that except in the thighs, the prevalence of other disorders decreased. These findings suggest that implementing ergonomic PIs (replacing chairs and using ergonomic chairs, changing workstation layouts, and replacing a non-ergonomic mouse, providing a sheet holder, offering a mouse pad, adjusting the height of the monitor) along with administrative intervention (teaching people how to maintain proper posture while working, how to use the mouse and keyboard correctly, how to work with the phone correctly, adjusting the chair, using breaks during work, and doing soft movements behind the desk) has been able to significantly reduce MSDs in several areas of the body. Furthermore, the rate of decline, compared with the group receiving the education program, was greater. One of the most important reasons for the higher effectiveness of these interventions, compared with the EI group, can be the combined use of PIs with EIs. This approach is considered to be the most important and effective measure to improve ergonomic conditions in workplaces [22]. These results are consistent with studies, in which PIs have been used in addition to administrative (educational) interventions. In a study of four groups of computer users and office workers, Robertson et al. (2009) indicated that after 6 months of intervention, the reduction level in the prevalence of discomfort in the group receiving both physical and administrative interventions was higher than in the other three groups (control group, the EPI group, and the PI group) [36]. In the study conducted by Jahangiri et al. (2015), both PIs and EIs were introduced as a more appropriate approach than the use of administrative intervention (employee training) alone to reduce musculoskeletal discomfort [22]. The findings of studies conducted by Shariat et al. (2018) and Robertson et al. (2016) are consistent with the results of the present study [31,32].

\subsection{Study limitations}

One of the strengths of the present study was its large sample size. However, conducting this study with this high number of participants required a large amount of time and financial resources. It was conducted with the support of the supervisors of the study units. Additionally, the management commitment (unit supervisors) required to support the study, and the high participation of the surveyed staff may be one of the important factors in achieving results. The use of a specific method (ROSA) to assess risk factors causing MSDs in office occupations that incorporate many of the biomechanical risk factors associated with such occupations is another strength of the present study. One of the weaknesses of the present study is studying the prevalence of MSDs in the population using a self-reported questionnaire (Nordic musculoskeletal questionnaire), because this method may be affected by the subjects [23]. Finally, the results of the present study indicate the increased effect of both EPIs compared with EIs alone and confirm the use of the ROSA method in determining the type of interventions required.

\section{Conclusions}

Nine months after interventions, relative improvement in workstations and prevalence of MSDs was observed in the intervention groups. These findings suggest that implementing educational and physical intervention 
ergonomic will further reduce MSDs compared to educational intervention alone. Moreover, increasing employees' awareness of the ergonomic risk factors in office work, and the correct way to arrange and utilize office equipment can improve the workstation-through the employees themselves-and thus improve conditions.

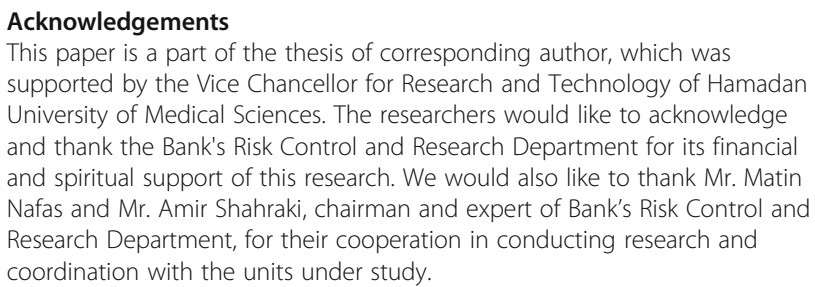
and spiritual support of this research. We would also like to thank Mr. Matin Nafas and Mr. Amir Shahraki, chairman and expert of Bank's Risk Control and Research Department, for their cooperation in conducting research and coordination with the units under study.

\section{Authors' contributions}

MM conceived and designed the study and wrote the first draft of the manuscript. MJ collected the data and drafted the manuscript. RG critically revised the manuscript and revised the final manuscript. JF performed the statistical analysis. HRZ facilitated data collection in the field. IN contributed to the conception and design of the study and supervised the data collection and Interventions Follow-up. All authors read and approved the final manuscript.

\section{Funding}

The researchers would like to acknowledge and thank the Bank's Risk Control and Research Department for its financial and spiritual support of this research. The cost of purchasing the equipment (chairs, footrest, document holder, etc.) is provided by the bank.

The researchers would like to acknowledge and thank the Vice-Chancellor of Research and Technology Birjand University of Medical Sciences for its financial and spiritual support of this research.

\section{Availability of data and materials}

The datasets generated during the current study are available on request.

\section{Declarations}

\section{Ethics approval and consent to participate}

This study was approved by the Ethics Committee of Hamadan University of Medical Sciences with reference number Ir.umsha.REC.1392.1924. To obtain informed consent from the subjects, the informed consent form was distributed. All the participants completed the written informed consent and signed it.

\section{Consent for publication}

The image of people for use in the article was blurred. Participants' consent was obtained to print their blurred images

\section{Competing interests}

The authors declare that they have no competing interests.

\section{Author details}

'Department of Ergonomics, School of Health and Research Center for Health Sciences, Hamadan University of Medical Sciences, Hamadan, Iran. ${ }^{2}$ Department of Occupational Health Engineering, School of Health, Neyshabur University of Medical Sciences, Neyshabur, Iran. ${ }^{3}$ Department of Occupational Health Engineering, School of Health, Isfahan University of Medical Sciences, Isfahan, Iran. ${ }^{4}$ Center of Excellence for Occupational Health, Occupational Health \& Safety Research Center, Hamadan University of Medical Sciences, Hamadan, Iran. ${ }^{5}$ Modeling of Noncommunicable Diseases Research Center \& Department of Biostatistics and Epidemiology, School of Public Health, Hamadan University of Medical Sciences, Hamadan, Iran. ${ }^{6}$ Ferdows School of Paramedical and Health, Birjand University of Medical Sciences, Birjand, Iran. ${ }^{7}$ Department of Ergonomics, Health Sciences Research Center, School of Health, Hamadan University of Medical Sciences, P.O. Box 65175-4171, Hamadan, Iran.
Received: 16 November 2020 Accepted: 16 November 2021

Published online: 11 December 2021

\section{References}

1. Rahimi Moghadam S, Mohammadyan M, Markani A, Khanjani N, Jalali M. Simulation of lead fume emissions in the workplace using computational fluid dynamics in the electronics industry. Environ Sci Pollut Res Int. 2020; 27(27):34250-7. https://doi.org/10.1007/s11356-020-09566-7.

2. Aliabadi $M$, Farhadian $M$, Jalali $M$, Jahangiri $M$, Negahban $A R$. A new empirical approach for predicting heat strain in workers exposed to hot indoor environments. Indoor Built Environ. 2018:27(5):597-605. https://doi. org/10.1177/1420326X16687800.

3. Jahangiri M, Golmohammadi R, Aliabadi M, Jalali M. Noise control of feed water pumps in a thermal power plant. Iran Occup Health. 2017;14(1):81-92. Persian.

4. Jalali M, Aliabadi M, Farhadian M, Negahban S. Investigation of the variation of urine density as abiomarker of dehydration conditions in workers employed in hot workplaces. Iran Occup Health. 2014;11(2):99-110 Persian.

5. Jalali M, Zare Sakhvidi MJ, Bahrami A, Berijani N, Mahjub H. Oxidative stress biomarkers in exhaled breath of workers exposed to crystalline silica dust by SPME-GC-MS. J Res Health Sci. 2016;16(3):153-61.

6. Yarahmadi $R$, Jalali $M$. The risk assessment of related factors of hand activities in automotive industry. Iran Occup Health. 2012;9(2):18-26 Persian.

7. Negahban A, Jalali M, Meshkani M, Rahimpoor R. Evaluation of risk factors in musculoskeletal disorders by HAL-TLV, SI and OCRA methods and comparison with other methods. J Rafsanjan Uni Med Sci. 2015;13(9):749-64 Persian.

8. Motamedzade M, Moradpour Z, Gorjizade H, Hesam G, Moghim BA. Design and fabrication of a personal digital assistant (PDA) prototype for postural assessment using RULA, REBA and QEC techniques. Iranian J Ergon. 2015; 2(4):32-40 Persian.

9. Jahangiri M, Najarkola SAM, Gholami T, Mohammadpour H, Jahangiri A, Hesam G, et al. Ergonomics intervention to reduce work-related musculoskeletal disorders in a lead mine. Health Scope. 2015;4(4). https:// doi.org/10.17795/jhealthscope-29507.

10. Mohammadpour H, Jalali M, Moussavi-Najarkola SA, Farhadi S, Kangavari M, Sartang AG. Ergonomic risk assessment of distal upper extremities by job strain index in carpet weavers. Health Scope. 2018;7(1):e64182. https://doi. org/10.5812/jhealthscope.64182.

11. World Health Organization. WHO global plan of action on workers' health (2008-2017): Baseline for implementation. Geneva, World Health Organization; 2013. Contract No.: WHO/FWC/PHE/2013.01

12. Rasoulzadeh Y, Gholamnia R. Effectiveness of an ergonomics training program on decreasing work-related musculoskeletal disorders risk among video display terminals users. Health Promot Perspect. 2012;2(1):89-98. https://doi.org/10.5681/hpp.2012.011.

13. Taieb-Maimon M, Cwikel J, Shapira B, Orenstein I. The effectiveness of a training method using self-modeling webcam photos for reducing musculoskeletal risk among office workers using computers. Appl Ergon. 2012:43(2):376-85. https://doi.org/10.1016/j.apergo.2011.05.015.

14. Jalali M. The risk assessment of related factors of hand activities in automotive industry. Iran Occup Health. 2012;9(2):18-26 Persian.

15. Wu S, He L, Li J, Wang J, Wang S. Visual display terminal use increases the prevalence and risk of work-related musculoskeletal disorders among Chinese office workers: a cross-sectional study. J Occup Health. 2012:54(1): 34-43. https://doi.org/10.1539/joh.11-0119-OA

16. Esmaeilzadeh S, Ozcan E, Capan N. Effects of ergonomic intervention on work-related upper extremity musculoskeletal disorders among computer workers: a randomized controlled trial. Int Arch Occup Environ Health. 2014; 87(1):73-83. https://doi.org/10.1007/s00420-012-0838-5.

17. Da Costa BR, Vieira ER. Risk factors for work-related musculoskeletal disorders: a systematic review of recent longitudinal studies. Am J Ind Med. 2010;53(3):285-323. https://doi.org/10.1002/ajim.20750.

18. Sihawong R, Sitthipornvorakul E, Paksaichol A, Janwantanakul P. Predictors for chronic neck and low back pain in office workers: a 1-year prospective cohort study. J Occup Health. 2015;58(1):16-24. https://doi.org/10.1539/joh.1 5-0168-OA.

19. Giahi O, Khoubi J, Barkhordari A, Darvishi E, Ebrahimzadeh M. Daily visual display terminal use and musculoskeletal disorders among Iranian bank tellers. J Advance Environ Health Res. 2014;2(1):22-8. https://doi.org/10.221 02/jaehr.2014.40136 
20. Melhorn JM. Epidemiology of musculoskeletal disorders and workplace factors. In: Gatchel RJ, Schultz IZ, editors. Handbook of musculoskeletal pain and disability disorders in the workplace. Switzerland: Springer; 2014. p. 175-204. https://doi.org/10.1007/978-1-4939-0612-3 10.

21. Ardahan M, Simsek H. Analyzing musculoskeletal system discomforts and risk factors in computer-using office workers. Pak J Med Sci. 2016;32(6): 1425-9. https://doi.org/10.12669/pjms.326.11436.

22. Jahangiri M, Najarkola SAM, Gholami T, Mohammadpour H, Jahangiri A, Hesam G, et al. Ergonomics intervention to reduce work-related musculoskeletal disorders in a lead mine. Health Scope. 2015;4(4):38-44. https://doi.org/10.17795/jhealthscope-29507.

23. Kuorinka I, Jonsson B, Kilbom A, Vinterberg H, Biering-Sørensen F, Andersson $\mathrm{G}$, et al. Standardised nordic questionnaires for the analysis of musculoskeletal symptoms. Appl Ergon. 1987;18(3):233-7. https://doi.org/1 0.1016/0003-6870(87)90010-X.

24. Mohammadipour F, Pourranjbar M, Naderi S, Rafie F. Work-related musculoskeletal disorders in iranian office workers: prevalence and risk factors. J Med Life. 2018;11(4):328-33. https://doi.org/10.25122/jml-20180054.

25. Besharati A, Daneshmandi H, Zareh K, Fakherpour A, Zoaktafi M. Workrelated musculoskeletal problems and associated factors among office workers. Int J Occup Saf Ergon. 2020;26(3):632-8. https://doi.org/10.1080/1 0803548.2018.1501238.

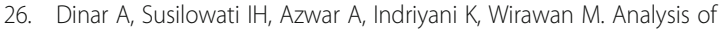
ergonomic risk factors in relation to musculoskeletal disorder symptoms in office workers. KnE Life Sci. 2018;4(5). https://doi.org/10.18502/kls.v4i5.2536.

27. Brandt M, Sundstrup E, Jakobsen MD, Jay K, Colado JC, Wang Y, et al. Association between neck/shoulder pain and trapezius muscle tenderness in office workers. Pain Res Treat. 2014;2014:352735. https://doi.org/10.1155/2 $014 / 352735$.

28. Hoe VC, Urquhart DM, Kelsall HL, Zamri EN, Sim MR. Ergonomic interventions for preventing work-related musculoskeletal disorders of the upper limb and neck among office workers. Cochrane Database Syst Rev. 2018;10(10):16-37. https://doi.org/10.1002/14651858.CD008570.pub3.

29. Poochada W, Chaiklieng S. Ergonomic risk assessment among call cente workers. Procedia Manuf. 2015;3:4613-20. https://doi.org/10.1016/j.promfg.2 015.07.543.

30. Sonne M, Villalta DL, Andrews DM. Development and evaluation of an office ergonomic risk checklist: ROSA-Rapid office strain assessment. Appl Ergon. 2012;43(1):98-108. https://doi.org/10.1016/j.apergo.2011.03.008.

31. Shariat A, Cleland JA, Danaee M, Kargarfard M, Sangelaji B, Tamrin SBM. Effects of stretching exercise training and ergonomic modifications on musculoskeletal discomforts of office workers: a randomized controlled trial. Braz J Phys Ther. 2018;22(2):144-53. https://doi.org/10.1016/j.bjpt.2017.09. 003.

32. Robertson MM. Huang Y-h, Larson N. The relationship among computer work, environmental design, and musculoskeletal and visual discomfort: examining the moderating role of supervisory relations and co-worker support. Int Arch Occup Environ Health. 2016;89(1):7-22. https://doi.org/10.1 007/s00420-015-1046-x.

33. Zeidi IM, Morshedi H, Zeidi BM. The effect of interventions based on transtheoretical modelling on computer operators' postural habits. Clin Chiropr. 2011;14(1):17-28. https://doi.org/10.1016/j.clch.2010.07.001.

34. Mahmud N, Kenny DT, Zein RM, Hassan SN. Ergonomic training reduces musculoskeletal disorders among office workers: results from the 6-month follow-up. Malays J Med Sci. 2011;18(2):16-26.

35. Motamedzade M, Mohseni M, Golmohammadi R, Mahjoob H. Ergonomics intervention in an Iranian television manufacturing industry. Work. 2011; 38(3):257-63. https://doi.org/10.3233/WOR-2011-1129.

36. Robertson M, Amick BC III, DeRango K, Rooney T, Bazzani L, Harrist R, et al. The effects of an office ergonomics training and chair intervention on worker knowledge, behavior and musculoskeletal risk. Appl Ergon. 2009; 40(1):124-35. https://doi.org/10.1016/j.apergo.2007.12.009.

37. Ali Arabian F, Motamedzade M, Golmohammadi R, Moghim Beigi A, Pir HF. The impact of ergonomics intervention on musculoskeletal disorders among Nahavand Alimoradian hospital staff. Iranian J Ergon. 2013;1(1):23-32 Persian.

\section{Publisher's Note}

Springer Nature remains neutral with regard to jurisdictional claims in published maps and institutional affiliations.

\section{Submit your manuscript to a SpringerOpen ${ }^{\circ}$ journal and benefit from:}

- Convenient online submission

- Rigorous peer review

- Open access: articles freely available online

- High visibility within the field

- Retaining the copyright to your article

Submit your next manuscript at $\boldsymbol{\nabla}$ springeropen.com 